\title{
Drawing as dialogue
}

\section{Brunetti, Federico Alberto}

Politecnico di Milano - Scuola del Design., Liceo Artistico di Brera, Milano, Italy

\begin{abstract}
The training paths, in the different levels and differentiation by age and specific orientations, are essentially based on the acquisition of knowledge in which the transmission of compentencies is organized starting and through the acquisition, and capacity for further modulation, of textual or alphanumeric languages. An area of particular intellectual value is however normally recognized and delegated to the activities defined as creative or artistic: that is, visual arts, or the choreutical and musical ones. The very concept of "vision", typical of the current methodologies of strategic thinking, refers to the ability to make visible the invisible, or to know how to conceive and communicate the experience of reality through interpretive hypotheses.

In Italy a new regulation called "School-Work Alternation" has been introduced in the training course of High Schools, for the development of those attitudes of so-called soft-skills in operational and relational responsibility, for a positive outlook in working contexts.

The case study of this manuscript concernes the students of the Liceo Artistico who forge their attitudes to know how to deal the conceptual mediations between visible and invisible, visual thinking and concept vision images. Drawing attitudes in fact accompanies the way they look at the world and elaborate a shareable image.These formative features have made their contributions in these experiences particularly interesting and original, not so much for non-profit creative collaborations that they have been able to develop with the Institutions that have welcomed them, but above all for the current image and innovative that they have been able to interpret and return.
\end{abstract}

Keywords: soft-skills; visual thinking; Drawing; strategic thinking, visual interpretive hypotheses 


\section{Introduction. Languages of learning: text and drawing}

The training paths, in the different levels and differentiation by age and specific orientations, are essentially based on the acquisition of knowledge in which the transmission of compentencies is organized starting and through the acquisition, and capacity for further modulation, of textual or alphanumeric languages. It is anthropologically evident how the organization of language and writing have been - and are - the interpretative algorithms that have made the human race able to develop memory as a shared and permanent factor through the generations; it is thanks to the learning of this shared code that education is founded through the communication of knowledge, models and archetypes.

The recent highlighting of soft skills through which behavioral attitudes, character and collaborative profiles can be oriented towards the interaction dynamics typical of complex organizations, remain based on the use of behavioral or linguistic or verbal languages in the communication of experiences and sharing of decisions and problems. An area of particular intellectual value is however normally recognized and delegated to the activities defined as creative or artistic: that is, visual arts, or the choreutical and musical ones. In this way what could be a synthetic and symbolic modality of strategic factor for the whole formation of personality and communication skills, both for personal as well as group attitude, is delegated / relegated to the skills of creativity. It has in fact been proven by various sources that the imaginative strategies characteristic of visual thought have a relevant importance in the identification of processes of high complexity that, in their proper conception and heuristic expression, can find positive solution and catalyze the dynamics necessary for their facing.

The very concept of "vision", typical of the current methodologies of strategic thinking, refers to a category - not necessarily only visual, but certainly related to the imagination the ability to make visible the invisible, or to know how to conceive and communicate the experience of reality through interpretive hypotheses. These ideational abilities can find in drawing - based both of observation from the reality, or on mnemonic or imaginary implementation, and conceptual or design prefiguration - can find different modalities of visual and graphic expression of particular importance for the personal growth. Through drawing, overcoming the stereotypes and self-inhibitions often fueled by the same scholastic imposition of coded alphanumerical languages, the person of any age can find not only an emotional pleasure, but also trace the paths of inner and cognitive processing that otherwise could remain latent and unexpressed. Moreover, it is known that in the practice of the so-called drawing from reality, or even mnemonic, some autobiographical activities characteristic of a holograph tract at the limit between graphics and writing are put into action: for example, the aptitude test of the drawing by hearth of a tree, has become a classic interpretation elaborate of the character of a person, even at very different ages. 


\section{Arts between Humanistics and Science. Artistic High School}

For these reasons a school where drawing is the fundamental cognitive and expressive language, even if renamed according to the specific disciplines taught (i.e.: geometric / figurative, architecture / painting, design / scenography, etc.) is at the center of an important evolution not only from the point of view of the "Arts" of which it is medium, but of the formation of creative thought, elaborated through education to image and to design. The educational program of the Artistic High School, upon which this manuscript is concerned, is located at this interesting crossroad: indeed while solidly humanistic and scientific subjects (defined cultural) remain, the orientation profile is directed towards the development of creative attitudes of the paths of the subsequent academic and university training, such as the Academies of Fine Arts or the Polytechnic Universities, or other postgraduate schools with a university profile. However it is well known how the scenario of the professions, and the relative training paths, are transforming themselves with diversification and application scenarios that are probably unpreceeded, if not unknown, in the present time and into of the relationship between teachers and students.

\section{A new soft skills learning experience and method}

In recent years, in order to introduce without any hesitation the so-called soft-skills in the training courses, ie the "learning by doing" development of those attitudes of operational and relational responsibility necessary for a positive outlook in working contexts, in Italy a new regulation called "School-Work Alternation" has been introduced (among other European countries these educational protocols are named as: work-related learning, or young apprenticeship programme, or national vocational qualifications). Although with different difficulties -both organizational than bureaucratic and also various hesitations from different teachers who saw in this sudden innovation a problem rather than an opportunity- we can highlight in which way this experience has generated, if conducted with resilient collaboration, interesting experiences. Technical schools have traditionally interwoven collaborative relationships with their own territories, toward which their students had to be effectively formed for a fruitful insertion into the productive network. Differently the Liceums, usually oriented towards the prospect of pursuing towards university studies, have so far attended these frequentations or interactions with the territory as occasional or merely voluntary.

The reason for this distance lays both in the self-reference or institutional prudence of these kinds of high schools, as in the presumed awareness of the value of a theoretical knowledge up on the practical one, and upon in the organizational and bureaucratic difficulty of managing training times and roles that can be developed outside the institutions. 
This new legislation has made it compulsory for the last three years of high school in to perform a total of 200 hours of activities coordinated with external institutions, delegating the design of these training courses to the schools themselves and to their internal delegates. It should be emphasized that a social security profile for former student-workers was been dedicated provided by I.N.P.S., the state institution responsible for social insurance for occupational accidents, in order to protect any activity performed - after specific courses on safety - in this context.

The Arts high schools, and Liceuns, and in particular the one here presented as a case study, have found in this legislation simply an equipped path, or in any case to be configured, in order to carry out those interactions with external competences in the territory to which it would otherwise have been difficult to interact with.

Thanks to the requirements inherent in this training path, it was thus possible - although certainly with a considerable organizational and bureaucratic effort - to demonstrate how the attitudes to be cultivated through visual arts education implies and educates also to an ability to communicate with the drawing, making useful the presence of students in the interactions with the working structures of the Milan area.

\section{Dialogue through drawing}

It is possible to notice how the specific skills, acquired during the course of their studies by the students of the Liceo Artistico, have predisposed them to face with particular agility these experiences that have been offered to them in the extracurricular field. But even more interesting and significant were the interest, expectations and in general the positive appreciation that the institutions that hosted these alternative training experiences. In fact, just as the coordinators of the training projects of these conventions have been careful not to configure activities that could have introduce any conflict or overlap with the work activities within the company in order not to conflict with the activities in progress, as well as the interest of the host structures was often motivated by being able to check how the younger generations perceive and know how to represent the contents of their business, of their corporate or company identity, of their brand. The students of the Liceo Artistico are found for their course of study- and for their personal attitudes - to know how to deal with particular interest the conceptual mediations between visible and invisible, between visual thinking and concept vision images. Although sometimes without explicit theoretical awareness, but with great creative intuition, they do not find themselves in difficulty in the semantic modulations and representation between reality and its symbols. 
The act of Drawing, conceived and practiced in the many expressive technical characteristics and imaginative prefigurations that pre-empt it, accompanies the way they look at the world and elaborate a shareable image.

These formative characteristics have made their contributions in these "Alternanza Scuola Lavoro" experiences particularly interesting and original, not so much for non-profit creative collaborations that they have been able to develop with the metropolitan, cultural, artistic, scientific and design Institutions that have welcomed them, but above all for the current image and innovative that they have been able to interpret and return.
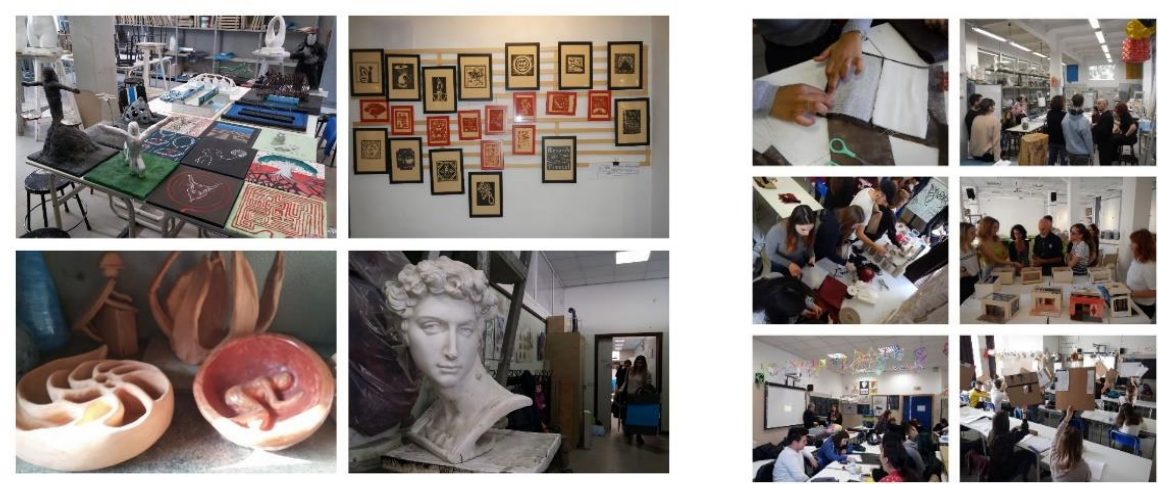

Figure 1. (left): sculptor and graphic workshops elaboration developed in the Laboratories of Artistic Liceum of Brera. Painting, and Scenography Courses: Source: picture of the author. https://www.liceoartisticodibrera.gov. it/ https://www.liceoartisticodibrera.gov.it/didattica/galleria-lavori/ http://www.liceoartisticodibrera.com/careers-in-art-artigianato-presso-le-gallerie-ditalial

Figure 2. (right) Liceo Artistico di Brera Team work - collaborative activities in diffent disciplines workshops and Laboratories : geometric / figurative, architecture / painting, design / scenography. Source: picture of the author. 

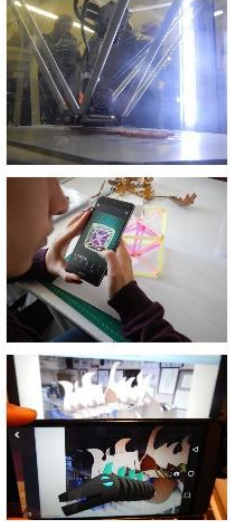
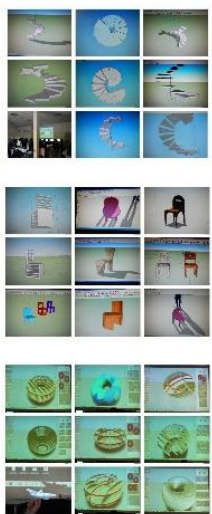
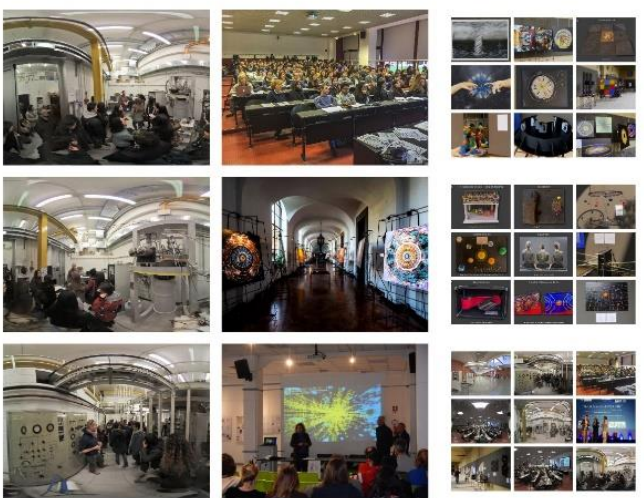
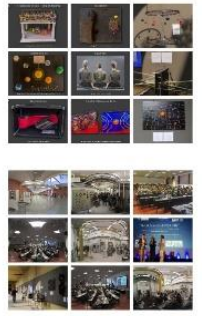

Figure 3 (left). Drawing digital process: 3D printer at work; analogic models smartphone macrophoto; virtual prototype overlapping in augmented reality; Design exercise modelling Lab in 3D sketchup sw.,

Figure 4. (right): "Arts \& Science Across Italy" national challenge: seminars at Liceo Brera and Università Bicocca with I.N.F.N. survey Laboratories. Source: picture of the author.

https://web.infn.it/artandscience/index.php/en/

http://www.liceoartisticodibrera.com/concorso-arte-scienza-esposizione-in-spazio-hajech-gli-anelli-del-sapere/ http://arts.cern/

http://www.artescienzaeconoscenza.it/
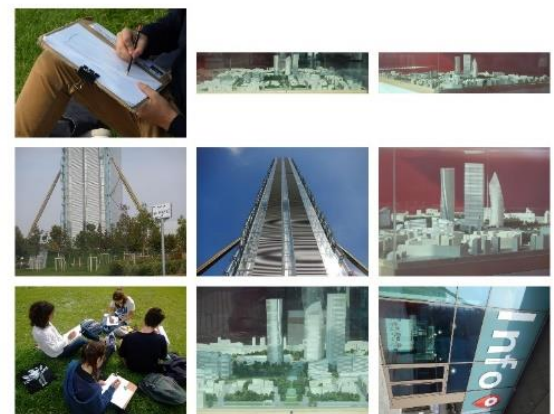
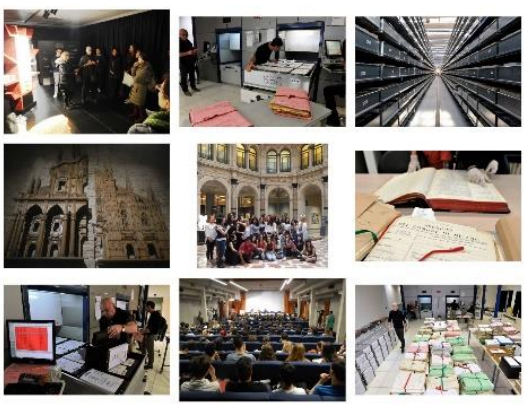

Figure 5. (left): Urban survey drawing from real sessions at Citylife Tre Torri skyscrapers development park, in the context of Accademia Fondazione Fiera Milano studies sessions. Source: picture of the author (2017).

Figure 6. (right): Frames of some study sessions in Intitutional sites (Museo del Design, Cittadella degli Archivi Comune di Milano; veneranda Fabbrica del Duomo di Milano, Gallerie d'Italia) Source: picture of the author:

http://www.comune.milano.ithps/portalistithews/primopiano/tutte_notizie/trasformazione_digitale_servizi/digitalizzazione_cittadella_degli_archivi 

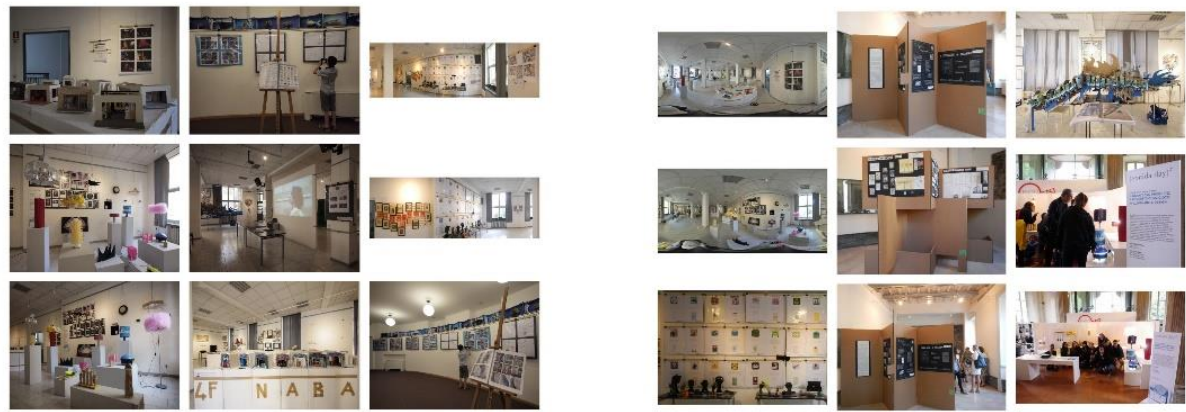

Figure 7. (left and right): some views of the final exibitons of students' works presented both in the Liceum hall, than into the gallery of some Istitution partners of the Alternanza Scuola - Lavoro: Acquario Civico, ISEC, ISAD, MuBa, Gallerie d'Italia Source: picture of the author (2017).

https://www.liceoartisticodibrera.gov.it/comunicazioni/alternanza-scuola-lavorol http://www.liceoartisticodibrera.com/esperienze-di-alternanza-scuola-lavorol http://www.liceoartisticodibrera.com/didattica/alternanza-scuola-lavoro/

http://www.liceoartisticodibrera.com/circ235 1617-mostra-disseminare-alternanza-alternanza-spreading/ http://www.liceoartisticodibrera.com/didattica/alternanza-scuola-lavoro/alternanza-scuola-lavoro-progetto-careers-in-art/ http://www.liceoartisticodibrera.com/acquario-civico-mostra-alternanza-liceo-brera-opening-2017-06-08-h-15/ http://www.liceoartisticodibrera.com/inaugurazione-mostra-cercare-raccontare-progettare/

\section{An extraordinary case of study. "Arts \& Science across Italy"}

This specific national competition takes part to the concomitance "Alternating School Work" rules and it is part of a broad research path and now with valid methodological and institutional references that legitimize its experimentation: "Art \& Science across Italy" is part of the European CREATIONS project of Horizon 2020 and is organized by the National Institute of Nuclear Physics and the CERN Experiment of CERN in Geneva. The project is aimed at high school students of the third and fourth year of Milan, Florence, Padua / Venice and Naples, and lasts for two years (2017-2018). In fact at CERN, since some years has triggered a broad discussion of mutual awareness and interest in quality view of knowledge, so not limited to the visual arts, but just the chance to try to understand and represent through every expression of the features arts invisible to reality that is the subject of scientific research. At a high level academic research, the Geneva-based research group ARTS@CERN has developed a series of collaborations inviting professional artists, on proposals of their projects through an international call, thus inviting a period of research and residence in contact with scientists and their work. The characteristics of these residential research art projects are among the most varied and have the intent of: “..promoting the dialogue between artists and particle physics. It fosters the creation of new expert knowledge in the arts by extending artists' practice in connection with fundamental research..". At high school training level, the specific competition "Arts \& Science Across Italy", is a specific initiative promoted by the CMS experiment, supported by a staff of experienced referents in 
scientific communication trought some Italian cities in which INFN is present with researchers and some experimental research centers and were organized presentation seminars, traveling exhibitions, visits to experiments, talks with scientists in schools. (About these initiative we can even quote a former first pioneristic project of this kind in Italy named "Adotta scienza e Arte": see in web references). A group of students of Artistic Liceum take so part also to this Institutional collaboration concerning the complex debate about visualization processes of Science. On one hand the binomial Art-Science can refer however to the objective datum of Nature and to the attempts of human intelligence engaged in the observation - direct or through the instrumental data - of the phenomena in the real world. On the other hand, the contiguity between Mathematics-Art deals with two conceptual universes, both originally abstract or intuitive, initially deriving (and only sometimes) the starting point from the real world, but moving forward and sublimating its elaborations towards a conceptual vision or a perceptive dimension. On other side the contiguity between Mathematics-Art deals with two conceptual universes, both originally abstract or intuitive, initially deriving (only sometimes) from the starting point of the real world, but moving and sublimating its elaborations towards a conceptual vision or a perceptive dimension. In both cases two different "characters" are matching: the disciplinary structure of the logical-formal reasoning remain essential at the basis of the theoretical or interpretative speculation, as for the artistic side it is fundamental the open the research to intuitive, symbolic and creative solutions. It is well known how the two logical and creative universes of human thought belong to two hemispheres - disciplinary and anatomical - specific and different, contiguous and synergic. Both constitute the founds of knowledge of the world and of oneself at work: in the act of observing, recognizing, naming and inventing.

\section{Learning and teaching in the millenials digital era. Conclusions}

An emphasis must be made on the fundamental support of teachers and tutors concerned at every level of all of these training experiences. In our transition era, after having gradually accompanied digital techniques between languages and intercommunication methods, they are also involved in the commitment to support the scenarios of innovations and discoveries that, thanks to these technologies, are making themselves available for research. If our generation of adults - researchers, teachers, parents - has crossed the threshold between one century and another, between analog and digital, now the generation of "millennials" is already digital and looks at the forms of thought of the twentieth century as a classicism to which you can inspire, in the same way with which it considers a design object - perceived for us as an originally innovative time - but considered today as "vintage". The metamorphic innovation of digital technologies, unfolds them with aptitudes of a resilient open mental openness. 
At the same time these youngs are sorrounded to a hypertrophic quantity of information that risks to complicate every possible decision. But in such a complex scenario their ability to connect past and future, images and words - far beyond the humanistic / scientific schemas of scholastic disciplines - appears as though they were merging multiple data synaptically from information platform, leaving us sometimes amazed and admired. Their "hi-tech skills" are probably more up-to-date than the adults around them, and it is hoped that in a forthcoming hypothetical 4.0 society they will be able to reinvent the professions that their parents could lose in a regenerative and responsible way, in automation processes, in a relationship that is already called "bottom-up": that is, in which young people can be able to train adults to use new technologies. Probably the most honest knowledge that we can participate with them is to share the rich awareness of the legacy of the past, to meet the scenarios of the unpredictable or explore the many forms of the unknown that is always before us.

\section{Acknowlegments}

Silvia Piardi, Head of the Department of Design, Politecnico di Milano, Italy

Emilia Ametrano, Dean of Liceo Artistico di Milano, Italy

A particular grateful mention concerns all the collegues and students who carefully supported with their creativity and skills this new formative experience, in the connection between the didactical institutions and productive and cultural stakeholders outreach.

\section{References \& web references}

Bateson G. (1997), Verso un'ecologia della mente, Milano,

Brunetti Federico, (2012) Attraverso il Disegno. Relazioni tematiche, tracce metodologiche e atti didattici per l'architettura ed il design. Reprint with translations.. Milano.

Ciappei C., M. Cinque (2014), Soft skills per il governo dell'agire, Milano,

Cimatti B. (2016), Definition, development, assessment of soft skills and their role for the quality of organizations and enterprises, in: International Journal for Quality Research, 1, pp. 97-130.

de Kerckhove D. (2008) Dall'alfabeto a internet. L'homme «littéré»: alfabetizzazione, cultura, tecnologia

Edwards, B. (1979). Drawing on the right side of the brain. A course in enhancing creativity and artistic confidence. Los Angeles - New York, J. P. Tarcher;

Golemand D. (2000), Lavorare con intelligenza emotiva, Milano,

Kerejean A. (2003), Le caractère plus importante que le CV, Paris, Editions d'Organisation.

Junco R.; Mastrodicasa J., (2007) Connecting To The Net. Generation: What Higher Education Professionals Need To Know About Today's Students, Washington, DC, NASPA,

Mayer G.D., Solowey P. (1997), What is emotional intelligence? In: P. Solowey, J. D. Sluyter (eds.), Emotional development and emotional intelligence: Implications for educators, New York, Basic Books, pp. 3-31.

Notarbartolo D., Graffigna D. (2010), Scrivere è ... ; Grammatica Nuova, Firenze, 
Drawing as dialogue

OMS (1993), Skills for Life, Geneve.

Prensky M., (2001) Digital Natives, Digital Immigrants Part 1, in On the Horizon,.

Vittadini G. (2016), in: Heckman J.J., Kautz T., Formazione e valutazione del capitale umano, pp. 7-24

Zendler Egon. (2011), Encounters. Visionaries and Architects

https://www.sciencedirect.com/science/article/pii/S0747563215004008

https://it.wikipedia.org/wiki/Generazione ZZ https://it.wikipedia.org/wiki/Generazione $Y$

https://singularityhub.com/2018/01/30/nothing-cuts-through-complexity-like-visual-thinking/ 